\title{
REVIEW
}

\section{Functional proteomics, human genetics and cancer biology of GIPC family members}

\begin{abstract}
Masaru Katoh ${ }^{1}$
GIPC1, GIPC2 and GIPC3 consist of GIPC homology 1 (GH1) domain, PDZ domain and GH2 domain. The regions around the GH1 and GH2 domains of GIPC1 are involved in dimerization and interaction with myosin VI (MYO6), respectively. The PDZ domain of GIPC1 is involved in interactions with transmembrane proteins [IGF1R, NTRK1, ADRB1, DRD2, TGF $3 R 3$ (transforming growth factor $\beta$ receptor type III), SDC4, SEMA4C, LRP1, NRP1, GLUT1, integrin $\alpha 5$ and VANGL2], cytosolic signaling regulators (APPL1 and RGS19) and viral proteins (HBc and HPV-18 E6). GIPC1 is an adaptor protein with dimerizing ability that loads PDZ ligands as cargoes for MY06-dependent endosomal trafficking. GIPC1 is required for cell-surface expression of IGF1R and TGFßR3. GIPC1 is also required for integrin recycling during cell migration, angiogenesis and cytokinesis. On early endosomes, GIPC1 assembles receptor tyrosine kinases (RTKs) and APPL1 for activation of PI3K-AKT signaling, and G protein-coupled receptors (GPCRs) and RGS19 for attenuation of inhibitory G $\alpha$ signaling. GIPC1 upregulation in breast, ovarian and pancreatic cancers promotes tumor proliferation and invasion, whereas GIPC1 downregulation in cervical cancer with human papillomavirus type 18 infection leads to resistance to cytostatic transforming growth factor $\beta$ signaling. GIPC2 is downregulated in acute lymphocytic leukemia owing to epigenetic silencing, while Gipc2 is upregulated in estrogen-induced mammary tumors. Somatic mutations of GIPC2 occur in malignant melanoma, and colorectal and ovarian cancers. Germ-line mutations of the GIPC3 or MYO6 gene cause nonsyndromic hearing loss. As GIPC proteins are involved in trafficking, signaling and recycling of RTKs, GPCRs, integrins and other transmembrane proteins, dysregulation of GIPCs results in human pathologies, such as cancer and hereditary deafness.
\end{abstract}

Experimental \& Molecular Medicine (2013) 45, e26; doi:10.1038/emm.2013.49; published online 7 June 2013

Keywords: actin dynamics; cancer antigen; endocytic transport; Frizzled; planar cell polarity; whole-genome sequencing

\section{INTRODUCTION}

GIPC1/GIPC (GAIP/RGS19-interacting protein), ${ }^{1}$ GIPC2 ${ }^{2}$ and $\mathrm{GIPC}^{3}$ are PDZ domain proteins that constitute the GIPC family. ${ }^{4}$ GIPC1 is also known as TIP2 (Tax-interacting protein 2), ${ }^{5}$ NIP [neuropilin 1 (NRP1)-interacting protein], ${ }^{6}$ GLUT1CBP [GLUT1 (SLC2A1) C-terminal binding protein], ${ }^{7}$ SEMCAP1 [Semaphorin 4C (SEMA4C)-interacting protein 1], Synectin [Syndecan 4 (SDC4)-interacting protein $]^{9}$ and IIP1 [insulin-like growth factor-1 receptor (IGF1R)-interacting protein 1]. ${ }^{10}$ GIPC3 is also known as DFNB15, DFNB72, DFNB95 and C19orf64. ${ }^{11,12}$

Physiological roles of GIPC1 have been well characterized. The PDZ domain in the middle region of GIPC1 is involved in interaction with a variety of PDZ ligands, such as RGS19, NRP1, GLUT1, SEMA4C, SDC4 and IGF1R. ${ }^{1,6-10}$ The $\mathrm{N}$-terminal region of GIPC1 is involved in dimerization, whereas the C-terminal region of GIPC1 is involved in interaction with the retrograde motor protein, myosin VI
(MYO6). ${ }^{13-15}$ On the basis of these protein-protein interactions, GIPC1 functions as an adaptor molecule for loading PDZ-target cargoes on the MYO6 motor protein (Figure 1a).

GIPC family members are evolutionarily conserved with functional similarity. ${ }^{1-4,16-24}$ GIPCs are involved in the trafficking of various transmembrane proteins and regulate a variety of cellular processes, such as proliferation, planar cell polarity, cytokinesis and migration. Pathologies associated with the GIPCs, such as hearing loss ${ }^{11,12}$ and cancer, ${ }^{25-34}$ are emerging topics in the medical sciences. Here, the functional proteomics, evolutionary genetics, human genetics and cancer biology of the GIPC family members will be reviewed, with a focus on recent advances and future directions.

\section{GIPC FAMILY}

The GIPC1 gene at human chromosome 19p13.12, the GIPC2 gene at human chromosome $1 \mathrm{p} 31.1$ and the GIPC3 gene at

Division of Integrative Omics and Bioinformatics, National Cancer Centre, Tokyo, Japan

Correspondence: Dr Masaru Katoh, Division of Integrative Omics and Bioinformatics, National Cancer Centre, 5-1-1 Tsukiji, Chuo Ward, Tokyo 104-0045, Japan.

E-mail: mkatoh-kkr@umin.ac.jp

Received 31 March 2013; accepted 4 April 2013 

a

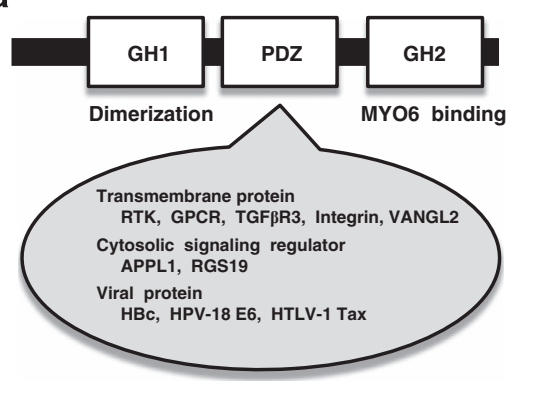

b

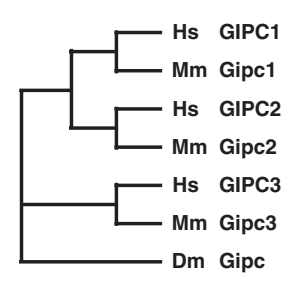

c

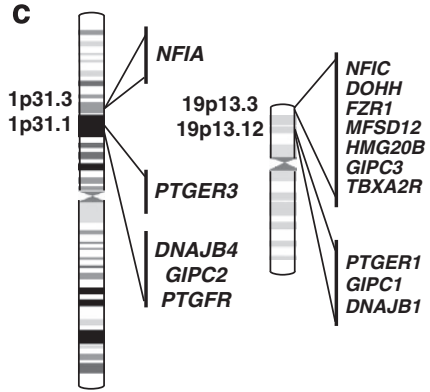

d

GH1 domain

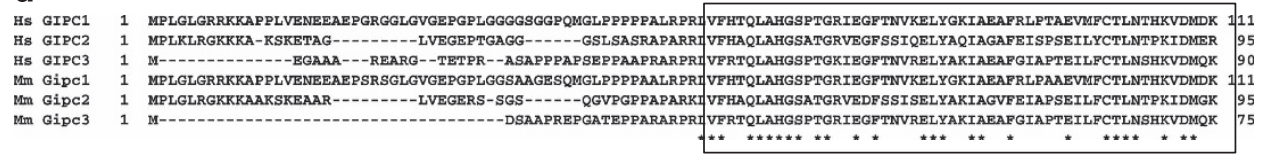

PDZ domain

HS GIPC1 112 LLGGIGLEDFIFAH KKQRRK VVEVFKSEDALGLTITDNGAGYAFIKRIKEGSVIDHIHLISVGDMIEAINGQSLLGCRHYEVARLLKELPRGRTFTLKLTEARKAFDMIS 222 HS GIPC2 96 LLGQLGLEDFIFAH TKGIEK QVNVYKSEDSLGLTI TDNGVGYAFIKRIKDGGVIDSVKTICVGDHIESTNGENIVGWRHYDVAKKLKELKKEELFTMKLIEP KKAFE-IE 205

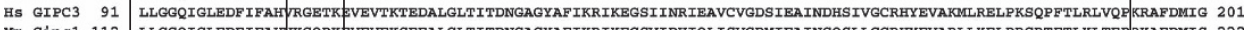
Mm Gipc1 112 LLGGQIGLEDFIFAH KGQRK FVEVFKSERALGLTITDNGAGYAFIKRIKEGSVIDHIQLISVGDMIEAINGQSLLGCRHYEVARLLKELPRGRTFTLKLTEERRKAFDMIS 222 Min Gipc2 96 LLGGLLGLDFIFAH KGTKKF VNVYKSEDSLGLTITDNGVGYAFIKRIKDGSTIDSVKTICVGDHIECINGENIVGWRHFEVAKKLKELKKEELFTLQLIEE KKAFE-IG 205 Mm GiPC3 76 LLGGQIGLEDFIFAH YRGETKEVEVTKTEDALGLTITDNGAGYAFIKRIKEGSIINRIEAVCVGDSIEAINDHSIVGCRHYEVAKMLRELPKSQPFTLRIVQE RRAFDMIG 186

GH2 domain

HS GIPC1 223 QRSAGGRPGSGPQLGT ERGTLRLRSRGPATVEDLPSAFEEKAIEKVDDLLESYMGIRDTELAATMVELGKDKRNPDELAEALDERLGDFAFPDEFVFDVWGAIGPAKVGRY 33 Hs GIPC2 206 LRSKAGK-SSGEKIGC FRATLRLRSKGPATVEEMP SETKAKAIEKIDDVLELYMGIRDIDLATTMFEAGKDKVNPDEFAVALDETLGDFAFPDEFVFDVWGVIGPAKRRGL 31 Hs GIPC 202 QRSRSSKCPVEAKVTS ERETLRLRSGGAATVEEAPSEFEEEASRKVDDLLESYMGIRDPELASTMVETSKKTASAQEFARCLDSVLGEFAFPDEFVVEVWAAIGEAREACG 312 MM GIDC1 223 QRSAGGHPGSPQLGTERGTLRLRSRGPATVEDLPSAFEEKAIEKVDDLLESYMGIRDTELAATMVELGKDKRNPDELAEALDERLGDFAFPDEFVFDVWGAIGPAKVGRY 333

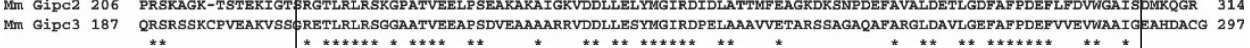

$* * * * * * * * * * * * * * *$ $* * * * * * * * * * * * * * *$

Figure 1 GIPC family. (a) Domain architecture of GIPC. GIPC family proteins consist of a GH1 domain, a PDZ domain and a GH2 domain. The regions around the GH1 and GH2 domains of GIPC1 are involved in dimerization and interaction with myosin VI (MYO6), respectively. The PDZ domain of GIPC1 is involved in interactions with transmembrane proteins, cytosolic signaling regulators and viral proteins. (b) Phylogenetic analyses of GIPC family proteins. GIPC1 and GIPC2 are more closely related. (c) Human chromosomal localization of GIPC family genes. (d) Alignment of human and mouse GIPC family proteins. The amino-acid position is shown on both sides of the alignment. Conserved amino acids are indicated by an asterisk below the alignment. The GH1 domain in the N-terminal part, PDZ domain in the middle part and GH2 domain in the C-terminal part are well conserved among GIPC family members. Dm, Drosophila; Hs, human; Mm, mouse.

human chromosome 19p13.3 constitute the human GIPC gene family. ${ }^{4}$ Phylogenetic analysis of human GIPC1 (NP_005707.1), GIPC2 (NP_060125.4), GIPC3 (NP_573568.1), mouse Gipc1 (NP_061241.1), Gipc2 (NP_058563.1), Gipc3 (NP_683753.1) and Drosophila Gipc (NP_652028.1) proteins reveals that GIPC1 is the paralog of GIPC2 (Figure 1b). The GIPC1 gene is located between the PTGER1 and DNAJB1 genes; the GIPC2 gene adjoins the DNAJB4 gene and lies close to the PTGER3 gene. The PTGER1-GIPC1-DNAJB1 and PTGER3-DNAJB4-GIPC2 loci are paralogous regions in the human genome (Figure 1c).

GIPC family proteins consist of a GIPC homology 1 (GH1) domain, a PDZ domain and a GH2 domain (Figure 1a). The GH1, PDZ and GH2 domains are well conserved among GIPC1, GIPC2 and GIPC3 orthologs (Figure 1d), as previously reported. ${ }^{4}$

\section{PROTEIN-PROTEIN INTERACTIONS OF GIPC1}

Protein-protein interactions have been comprehensively characterized for GIPC1, the founding member of the GIPC family (Figure 1a).
The PDZ domain of GIPC1 is involved in direct interactions with a variety of proteins, including adrenergic receptor $\beta 1$ (ADRB1), ${ }^{35}$ APPL1, ${ }^{36-38}$ CD93 (C1QR1), ${ }^{39}$ dopamine receptor D2 (DRD2), ${ }^{40}$ endoglin, ${ }^{41}$ GLUT1, ${ }^{7}$ IGF1R, ${ }^{10,27}$ integrin $\alpha 5,{ }^{42}$ integrin $\alpha 6,{ }^{42}$ luteinizing hormone/choriogonadotropin receptor (LHCGR), ${ }^{43}$ LRP1, ${ }^{44}$ LRP2 (megalin) ${ }^{44}$ NRP1, ${ }^{6,45,46}$ NTRK1 (TrkA), ${ }^{47}$ RGS19, ${ }^{1}$ SDC4, ${ }^{9}$ SEMA4C, ${ }^{8}$ transforming growth factor $\beta$ (TGF $\beta$ ) receptor type III (TGF $\beta \mathrm{R} 3),{ }^{48-50}$ trophoblast glycoprotein (TPBG), ${ }^{51}$ TYRP1 ${ }^{52}$ and Vang-like 2 (VANGL2 or STB1). ${ }^{53}$ IGF1R and NTRK1 are receptor tyrosine kinases (RTKs) with a single transmembrane domain; ADRB1, DRD2 and LHCGR are G protein-coupled receptors (GPCRs) with seven transmembrane domains; CD93, endoglin, GLUT1, integrin $\alpha 5$, integrin $\alpha 6$, LRP1, LRP2, NRP1, SDC4, SEMA4C, TGFBR3, TPBG, TYRP1 and VANGL2 are also transmembrane proteins (Figure 2). APPL1 is a scaffold protein, interacting with GIPC1, NTRK1, Rab5, PIK3CA (the catalytic $\alpha$ subunit of phosphatidylinositol-4,5-bisphosphate 3-kinase (PI3K)) and AKT, ${ }^{36-38}$ while RGS19 is a regulator of $G$ protein signaling, interacting with GIPC and G protein $\alpha$ inhibitory subunit $3 .^{1}$ APPL1 and RGS19 are 


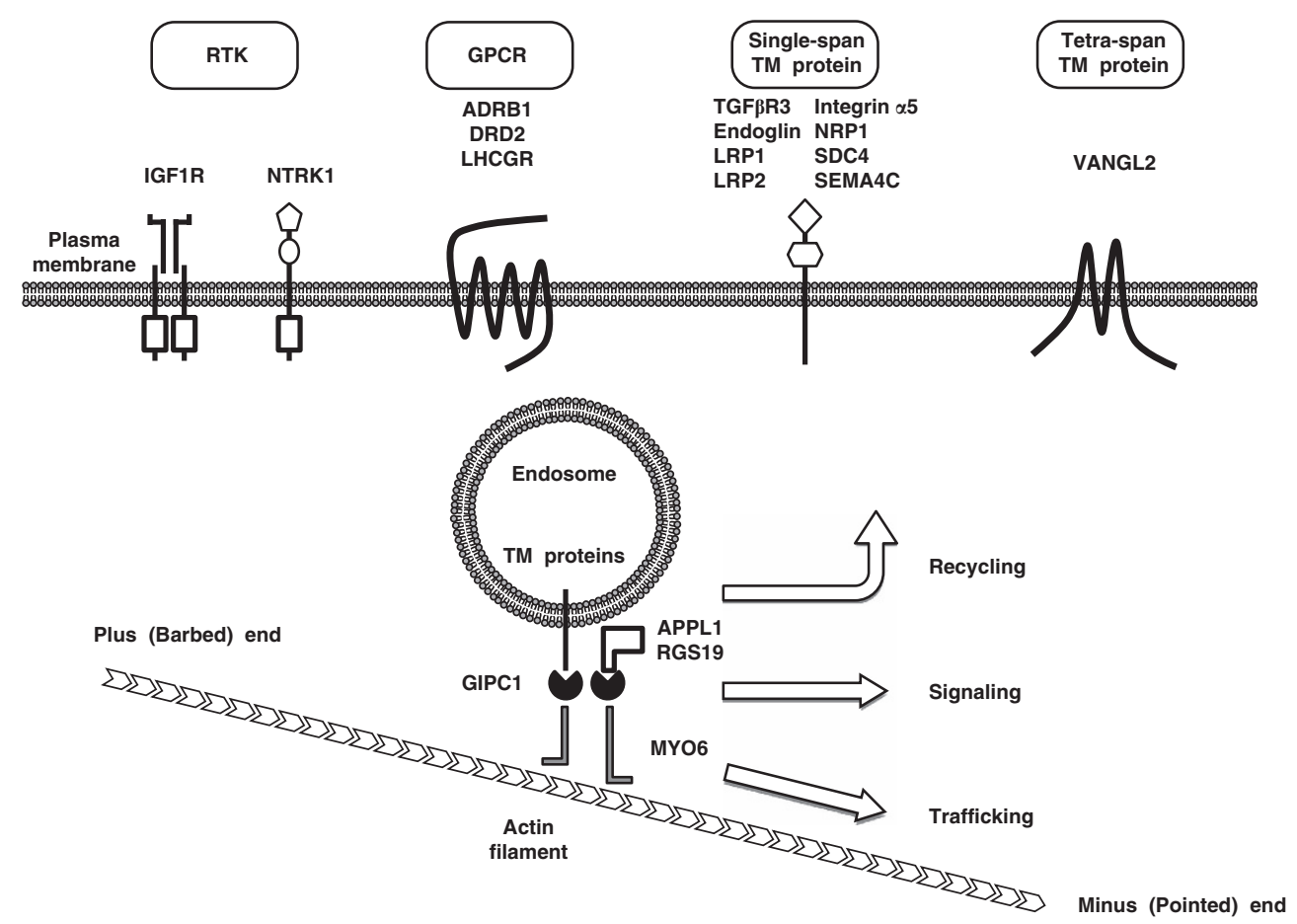

Figure 2 GIPC1-MYO6 complex-dependent trafficking of endocytic vesicles. GIPC1 is an adaptor protein that can interact with trafficking cargoes, while MYO6 is a motor protein that can move along actin filaments from the plus (barbed) end near the plasma membrane to the minus (pointed) end in the cytoplasm. Representative cargoes of the GIPC1-MYO6 complex are classified into receptor tyrosine kinases (RTKs; IGF1R and NTRK1), G protein-coupled receptors (GPCRs; ADRB1, DRD2 and LHCGR), single-span transmembrane (TM) proteins (TGF $\beta R 3$, endoglin, LRP1, LRP2, integrin $\alpha 5$, NRP1, SDC4 and SEMA4C), tetra-span TM protein (VANGL2) and cytosolic signaling regulators (APPL1 and RGS19). The GIPC1-MYO6 complex is directly involved in trafficking and signaling and is indirectly involved in the recycling of its cargoes.

cytosolic proteins that regulate intracellular signaling. In addition to the cellular proteins mentioned above, the PDZ domain of GIPC1 directly interacts with viral proteins, such as $\mathrm{HBc},{ }^{54} \mathrm{E} 6^{55}$ and Tax, ${ }^{5}$ which are derived from the hepatitis B virus, human papillomavirus type 18 (HPV-18) and human T-cell leukemia virus type 1 , respectively. The majority of PDZ ligands for GIPC1 are transmembrane proteins, but a minority of them are cytosolic signaling regulators.

The C-terminal region around the GH2 domain of GIPC1 can directly interact with MYO6, a member of the myosin family of motor proteins. ${ }^{13-15}$ MYO6 moves toward the minus (pointed) end of actin filaments located in the cytoplasm, whereas other myosin family proteins move toward the plus (barbed) end of actin filaments adjacent to the plasma membrane. MYO6 is a retrograde motor protein, involved in various cellular processes such as trafficking of early endosomes, cytokinesis and migration. ${ }^{56}$

The N-terminal region around the GH1 domain of GIPC1 is involved in dimerization. ${ }^{13}$ Because of its dimerization potential, GIPC1 is able to assemble PDZ-binding proteins as cargoes of the MYO6 motor protein in early endosomes (Figure 2).

\section{INTRACELLULAR FUNCTIONS OF GIPC1}

Transmembrane proteins on the plasma membrane are internalized and packed into inside-out vesicles as a result of endocytosis. ${ }^{57}$ The endocytic vesicles are initially located in the periphery of the cytoplasm, beneath the plasma membrane, and are trafficked to early endosomes. ${ }^{58}$ As MYO6 is a motor protein moving along actin filaments from the barbed end near the plasma membrane to the pointed end in the cytoplasm, the GIPC1-MYO6 complex has a pivotal role in the trafficking of transmembrane proteins on endocytic vesicles (Figure 2). Most of transmembrane receptors on the early endosomes are returned to the plasma membrane directly or via recycling endosomes, although some of them are sorted for lysosomal degradation. GIPC1 is necessary for cell-surface expression of transmembrane receptors, such as IGF1R, ${ }^{27}$ LHCGR $^{43}$ and TGFßR3. ${ }^{48}$

GIPC1 interacts with integrin $\alpha 5$ subunit, ${ }^{42}$ which is bound to integrin $\beta$ subunit to form integrin heterodimers. Integrin $\alpha 5 \beta 1$ is trafficked to the early endosomes as a cargo of the GIPC1-MYO6 complex and is then sorted for recycling to the plasma membrane. As integrins are mechano-sensory receptors that bridge extracellular matrix and cytoplasmic adaptor proteins associated with actin filaments, integrin recycling to cell surface is required for the regulation of actin dynamisms. ${ }^{59,60}$ Indeed, GIPC1 is required for the trafficking of internalized integrins during cell migration, ${ }^{19}$ angiogenesis ${ }^{61}$ and cytokinesis. ${ }^{15}$

RTKs consist of an extracellular ligand-binding domain, a transmembrane domain and a cytoplasmic tyrosine kinase domain. RTKs are receptors for growth factors, such as 
epidermal growth factor, IGF1, nerve growth factor and fibroblast growth factor. ${ }^{62-64}$ The binding of ligands to RTKs induces their dimerization and autophosphorylation, which leads to the activation of RAS-ERK, PI3K-AKT, phospholipase $\mathrm{C} \gamma$ (PLC $\gamma)$ and other signaling cascades. RTKs are internalized as a result of ligand-induced dimerization. RTK signaling occurs from the plasma membrane as well as early endosomes. ${ }^{62,63}$ GIPC1 binds to IGF1R and NTRK1 but not to insulin receptor, ${ }^{10,47}$ and enhanced endosomal signaling occurs from NTRK1 but not from insulin receptor. ${ }^{63}$ As PI3K and AKT are recruited to the GIPC complex via interactions with APPL1, GIPC1 dimers induces clustering of RTK and APPL1 complex to early endosomes for the preferential activation of the PI3KAKT signaling cascade rather than the RAS-ERK signaling cascade. ${ }^{36-38}$ GIPC1 is involved in the endosomal signaling from RTK to the PI3K-AKT signaling cascade (Figure 3a).

GPCRs consist of extracellular ligand-binding regions, seven transmembrane domains and cytoplasmic $G$ protein-binding regions. GPCRs are receptors for a variety of ligands, such as adrenaline (epinephrine), dopamine and WNT. ${ }^{65,66}$ Ligand binding to GPCRs induces dissociation of heterotrimeric G proteins from GPCRs, leading to the activation of $\mathrm{G} \alpha$ - and G $\beta \gamma$-mediated signaling cascades. The G $\alpha$ s subunit activates adenylate cyclase to increase cyclic AMP concentrations. The inhibitory $\mathrm{G} \alpha(\mathrm{G} \alpha \mathrm{i})$ subunit inhibits adenylate cyclase to decrease cyclic AMP concentrations. The G $\alpha \mathrm{q}$ subunit activates PLC $\beta$. G $\alpha 12 / 13$ subunit activates Rho GTPase. The G $\beta \gamma$ subunit activates PI3K, PLC $\beta$ and ion channels. ${ }^{67}$ GPCRs are internalized as a result of ligand-induced dissociation of the heterotrimeric $\mathrm{G}$ proteins and subsequent association with $\beta$-arrestin. GPCR signaling occurs from the plasma membrane as well as from early endosomes. ${ }^{68}$ As RGS19 functions as a GTPase-activating protein to inactivate G $\alpha$ i, the dimerization of GIPC1 induces clustering of GPCR and RGS19 to the early endosomes for the attenuation of G $\alpha$ i signaling. ${ }^{35,40}$ GIPC1 is involved in the modulation of the endosomal GPCR signaling (Figure 3b).

Together, these facts indicate that GIPC1 regulates a variety of cellular processes, such as endosomal trafficking, signaling and recycling of RTKs, GPCRs, integrins and other transmembrane proteins.

\section{EVOLUTIONARILY CONSERVATION OF GIPCS}

Kermit 1 and Kermit 2 are Xenopus orthologs of human GIPC2 and GIPC1, respectively. Kermit 1 interacts with WNT receptors, including Frizzled-3 (Fzd3) and Frizzled-7 (Fzd7), and is required for WNT signaling during neural crest development. ${ }^{16}$ Kermit 2 interacts with Igflr similar to the interaction of human GIPC1 with IGF1R and is required for IGF1 signaling during eye development. ${ }^{17}$ Kermit 2 also interacts with the integrin $\alpha 5$ subunit to regulate endocytosis of $\alpha 5 \beta 1$ integrin, which is essential for the lining of the fibronectin matrix on the blastocoel roof during the gastrulation stage of embryogenesis. ${ }^{19}$

Zebrafish Gipc1 genetically interacts with Neuropilin-2 (Nrp2) and Vegfr3 (Flt4), and is involved in lymphangiogenic sprouting during thoracic duct formation. ${ }^{20} \mathrm{Nrp} 2$ functions as a co-receptor for the Vegfr3 ligands, Vegf-c and Vegf-d. Nrp2 and Nrp1 are paralogs, sharing a common domain architecture, especially the C-terminal PDZ-binding site. As
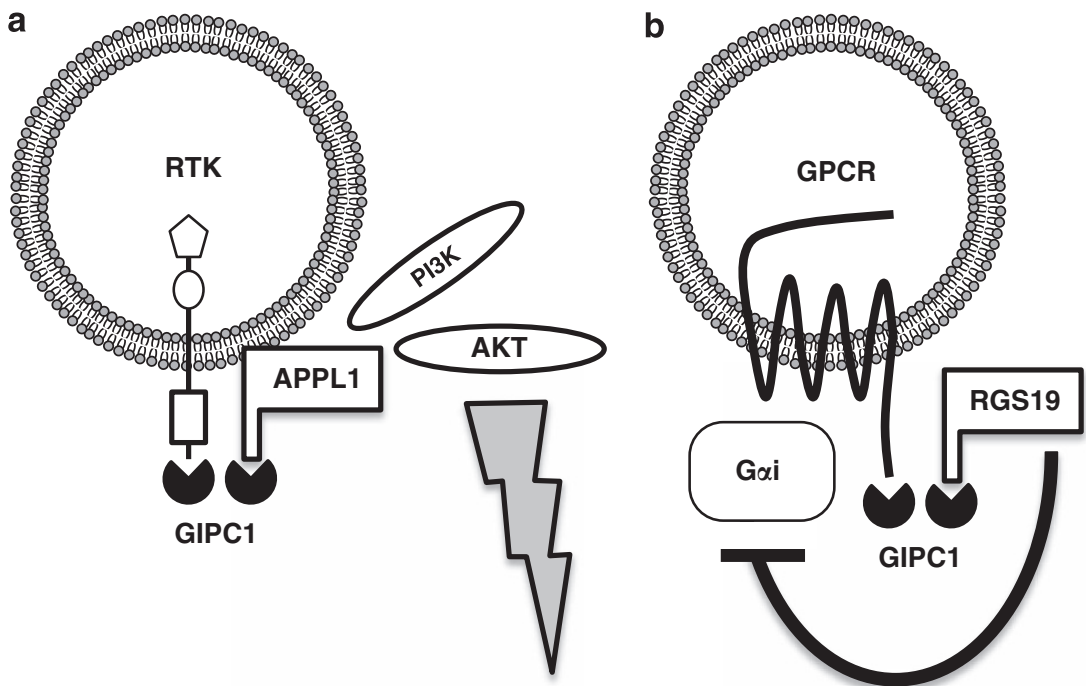

Figure 3 Involvement of GIPC1 in endosomal signaling. (a) GIPC1-mediated early endosomal signaling from receptor tyrosine kinases (RTKs). IGF1R and NTRK1 are GIPC1-interacting RTKs, while APPL1 is a scaffold protein that interacts with GIPC1, RTK, Rab5, PI3K and AKT. GIPC1-RTK and GIPC1-APPL1 complexes are assembled on early endosomes through GIPC1 dimerization or RTK-APPL1 interaction. Internalized RTKs clustered with APPL1 preferentially activate the PI3K-AKT signaling cascade. (b) GIPC1-mediated early endosomal signaling from G protein-coupled receptors (GPCRs). Adrenergic receptor $\beta 1$ (ADRB1) and dopamine receptor D2 (DRD2) are

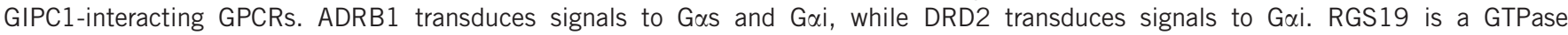
activating protein that can inactivate Gai. GIPC1-GPCR and GIPC1-RGS19 complexes are assembled on early endosomea through GIPC1 dimerization. RGS19 clustered with internalized GPCRs attenuates Gai signaling. 
mouse Gipcl directly interacts with the C-terminal tail of Nrp $1,{ }^{6}$ the interaction between Gipc1 and Nrp2 is thought to be required for lymphangiogenic signaling through the Nrp2Vegfr3 receptor complex.

Drosophila gipc mRNA is upregulated during wing development $^{21}$ and its overexpression causes planar cell polarity defects in the wing but not in the eye. ${ }^{22}$ Drosophila gipc does not genetically interact with core planar cell polarity components, such as frizzled, dishevelled, flamingo, strabismus (vang) and prickle; however, it does interact with jaguar, which is the Drosophila ortholog of human MYO6.

The Drosophila Gipc protein is expressed in the adult brain, especially in the dopaminergic neurons and glia. ${ }^{23}$ Drosophila gipc mutants show a reduction of dopaminergic neurons in the dorsomedial regions of the adult brain, which results in locomotor defects and reduced longevity. Although the interaction between Drosophila Gipc and the dopamine receptor remains unclear, interactions between rat Gipc and dopamine receptors suggest that Drosophila Gipc might also be involved in dopamine signaling.

Schistosoma japonicum is a pathogenic parasite that causes schistosomiasis. The expression level of S. japonicum gipc mRNA is relatively higher during the parasitic stages than during the cercarial stage, and S. japonicum Gipc interacts with the C-terminal tail of the glutamate receptor. ${ }^{24}$

GIPC proteins are conserved from mammals and other vertebrates to non-vertebrates, such as flies and worms, and some functions of GIPCs are also evolutionarily conserved.

\section{GIPC3 MUTATIONS IN FAMILIAL HEARING LOSS}

Germ-line homozygous mutations of human GIPC3 are associated with familial hearing loss, such as the autosomal recessive nonsyndromic hearing impairment DFNB15, DFNB72 and DFNB95. ${ }^{11,12,69}$ Human GIPC3 is almost ubiquitously expressed in adult human tissues, and the expression level of GIPC3 is relatively high in the small intestine, lymph node, brain parietal lobe, fetal spleen and fetal thymus. ${ }^{3}$ G46R, M88I and G94D missense mutations are located within the GH1 domain; H170N and R189C missense mutations are located within the PDZ domain; T221I, G256D, L262R missense mutations, W301X nonsense mutation and A229GfsX10 frame-shift mutation are located within the GH2 domain. G46, M88, G94, H170, T221, G256, L262 and W301 amino-acid residues of GIPC3 are conserved in all human and mouse GIPC family members (Table 1).

In line with hereditary deafness caused by mutations of human GIPC3, germ-line homozygous G115R mutations of Gipc3 occur in Black Swiss mice, which manifest progressive sensorineural hearing loss. ${ }^{11}$ Mouse Gipc3 mRNA is relatively highly expressed in the brain, lung and testes. ${ }^{70}$ G115 of mouse Gipc3, which corresponds to G130 of human GIPC3, is located within the PDZ domain. In Gipc3 mutant mice, the expression levels of the Gipc3 protein are decreased in the sensory hair cells of Corti's organ and their afferent neurons in the cochlear spiral ganglion, which is accompanied by disorientation and degradation of the stereocilia bundle of sensory hair cells and degradation of sensory neurons in the spiral ganglion, respectively. ${ }^{11}$

\section{CANCER BIOLOGY OF GIPC FAMILY MEMBERS}

GIPC1 is upregulated in human cancers, such as breast cancer, ${ }^{25,28,29,32}$ ovarian cancer ${ }^{26,28,34}$ and pancreatic cancer. ${ }^{25,27,31}$ GIPC1 is a cancer-associated auto-antigen, as anti-GIPC1 human monoclonal antibody was established from

Table 1 GIPC mutation spectra

\begin{tabular}{|c|c|c|c|c|c|c|}
\hline Gene & Type & Mutation & Location & Disease & Conservation & Reference \\
\hline GIPC1 & Somatic & F319L & $\mathrm{GH} 2$ domain & HNSCC & GIPC1, GIPC2 & 76 \\
\hline \multirow[t]{6}{*}{ GIPC2 } & Somatic & F74Y & GH1 domain & Colorectal cancer & GIPC1, GIPC2, GIPC3 & 77 \\
\hline & Somatic & G102E & GH1 domain & Ovarian cancer & GIPC1, GIPC2, GIPC3 & 79 \\
\hline & Somatic & D125N & PDZ domain & Malignant melanoma & GIPC1, GIPC2, GIPC3 & 78 \\
\hline & Somatic & E216X & & Colorectal cancer & & 77 \\
\hline & Somatic & E288K & $\mathrm{GH} 2$ domain & Malignant melanoma & GIPC1, GIPC2 & 78 \\
\hline & Somatic & R312Q & & Colorectal cancer & & 77 \\
\hline \multirow[t]{11}{*}{ GIPC3 } & Germ line & G46R & GH1 domain & Familial hearing loss & GIPC1, GIPC2, GIPC3 & 12 \\
\hline & Somatic & E67K & GH1 domain & Breast cancer & GIPC1, GIPC3 & 80 \\
\hline & Germ line & M88I & GH1 domain & Familial hearing loss & GIPC1, GIPC2, GIPC3 & 12 \\
\hline & Germ line & G94D & GH1 domain & Familial hearing loss & GIPC1, GIPC2, GIPC3 & 12 \\
\hline & Germ line & H170N & PDZ domain & Familial hearing loss & GIPC1, GIPC2, GIPC3 & 69 \\
\hline & Germ line & R189C & PDZ domain & Familial hearing loss & GIPC3 & 12 \\
\hline & Germ line & T221I & $\mathrm{GH} 2$ domain & Familial hearing loss & GIPC1, GIPC2, GIPC3 & 12 \\
\hline & Germ line & A229GfsX10 & $\mathrm{GH} 2$ domain & Familial hearing loss & & 12 \\
\hline & Germ line & G256D & $\mathrm{GH} 2$ domain & Familial hearing loss & GIPC1, GIPC2, GIPC3 & 12 \\
\hline & Germ line & L262R & $\mathrm{GH} 2$ domain & Familial hearing loss & GIPC1, GIPC2, GIPC3 & 11 \\
\hline & Germ line & W301X & $\mathrm{GH} 2$ domain & Familial hearing loss & GIPC1, GIPC2, GIPC3 & 11 \\
\hline
\end{tabular}

Abbreviations: GH2, GIPC homology 2; HNSCC, head and neck squamous cell carcinoma. 
a breast cancer patient. ${ }^{29}$ Immunohistochemical analyses using the anti-GIPC1 human monoclonal antibody revealed that the GIPC1 protein is overexpressed in primary breast cancer and ovarian cancer. ${ }^{28}$ GIPC1 overexpression in ovarian cancer is associated with amplification and overexpression of the ADRM1 gene, encoding a transmembrane protein that interacts with the UCH37 deubiquitinating enzyme. ${ }^{34}$ GIPC1, which is involved in IGF1R stabilization, promotes proliferation and survival of pancreatic cancer cells and breast cancer cells. ${ }^{27,31,32}$ GIPC1 knockdown in cancer cells inhibits proliferation and promotes apoptosis. GIPC1 knockdown also results in G2 cell-cycle arrest and deceased motility in MDA-MB231 cells, ${ }^{33}$ because GIPC1 is involved in cytokinesis $^{15}$ and cell migration. ${ }^{19}$ CR1023 (N-myristoylPSQSSSEA) is a cell-permeable octapeptide corresponding to the IGF1R-binding interface within the PDZ domain of GIPC1 that is able to inhibit the proliferation of IGF1Rdependent cancer cells by downregulating cell-surface IGF1R. ${ }^{31,32}$ CR1166 ( $N$-myristoyl-PSQSK( $\varepsilon N$-4-bromobenzoyl) $\mathrm{SK}(\varepsilon N$-4-bromobenzoyl)A) is the most active CR1023 derivative that downregulates both IGF1R and EGFR. ${ }^{71}$

GIPC1 is downregulated in cervical cancer associated with HPV-18 infection. ${ }^{55}$ The E6 oncoprotein derived from HPV-18 induces poly-ubiquitination and proteasomal degradation of GIPC1 using mechanisms similar to those observed for p53, Scribbled (SCRIB), MUPP1, MAGI1, MAGI2 and MAGI3. As GIPC1 enhances the cell-surface expression of TGF $\beta$ R3 and the cellular responsiveness to TGF $\beta,{ }^{48}$ E6-mediated GIPC1 downregulation results in decreased sensitivity to cytostatic TGF $\beta$ signaling. ${ }^{55}$

GIPC2 is upregulated in gastric cancer, ${ }^{72}$ whereas it is downregulated in kidney cancer, ${ }^{2}$ acute lymphocytic leukemia $(\mathrm{ALL})^{30}$ and adrenocortical carcinoma. ${ }^{73}$ The CpG island within the promoter region of the GIPC2 gene is hyper-methylated in all 23 leukemia cell lines, including MOLT4, Jurkat, Peer, T-ALL1, CEM, J-TAG, B-JAB, RS4, ALL1, Raji, REH and Ramos cells of lymphoid origin, as well as K562, BV173, HL60, NB4, THP1, U937, ML1, OCI, HEL, MOLM13 and KBM5R cells of myeloid origin. ${ }^{30}$ The GIPC2 promoter is also hypermethylated in 29 of the 31 cases of ALL. As GIPC2 repression in MOLT4, Jurkat, CEM, RS4 and Raji cells is restored after 5-aza-2'-deoxycytidine treatment, GIPC2 downregulation in primary ALL cases is predicted to be the result of epigenetic silencing-associated promoter hyper-methylation. ${ }^{30}$

Mouse Gipc2 is upregulated in estrogen-induced mammary lesions of Caveolin-1 knockout mice, which resembles human ductal carcinoma in situ. ${ }^{74}$ Mouse Gipc2 is specifically coexpressed with Esr1, which encodes estrogen receptor (ER), and Keratin 18 (Krt18) in the $\mathrm{ER}^{+}$luminal cells of the virgin mammary gland. ${ }^{75}$ These facts suggest the involvement of GIPC2 in human breast cancer of the $\mathrm{ER}^{+}$luminal type.

Somatic mutations of GIPC family genes have been identified based on whole-exome or whole-genome sequencing. F319L missense mutation of GIPC1 occurs in head and neck squamous cell carcinoma. ${ }^{76}$ F74Y and R312Q missense mutations and E216X nonsense mutation of GIPC2 occur in colorectal cancer. ${ }^{77}$ D125N and E288K missense mutations of GIPC2 occur in malignant melanoma. ${ }^{78}$ G102E missense mutation of GIPC2 occurs in ovarian cancer. ${ }^{79}$ E67K missense mutation of GIPC3 occurs in breast cancer. ${ }^{80}$ The F74Y, G102E and D125N missense mutations might alter GIPC2 functions, because the F74, G102 and D125 amino-acid residues of GIPC2 are conserved in all human and mouse GIPC family members (Table 1). The E216X nonsense mutation of GIPC2 in colorectal cancer is a deleterious mutation that results in a loss of the MYO6-binding GH2 domain.

\section{CONCLUSION}

GIPC proteins function as adaptor molecules that assemble RTKs, GPCRs, integrins, transmembrane proteins and cytoplasmic signaling regulators as cargoes of MYO6-dependent endocytic transport. Germ-line mutations of the GIPC3 gene occur in nonsyndromic hearing loss. Somatic mutations of GIPC family genes occur in several types of human cancers, such as head and neck squamous cell carcinoma, colorectal cancer, malignant melanoma, ovarian cancer and breast cancer. GIPC1 can be oncogenic or tumor suppressive in a contextdependent manner. As GIPCs are involved in trafficking, signaling and recycling of receptors and adhesion molecules, GIPC dysregulation results in a spectrum of human diseases, such as cancer and hereditary deafness.

\section{PERSPECTIVES}

Germ-line mutations of the human GIPC3 gene occur in autosomal recessive nonsyndromic hearing loss, such as DFNB15, DFNB72 and DFNB95, ${ }^{11,12,69}$ while those of human MYO6 gene occur in other types of familial hearing loss, such as DFNA22 and DFNB37. ${ }^{81,82}$ Mutations of mouse Gipc3 and Myo6 are also associated with hereditary hearing loss. ${ }^{11,83}$ GIPC1 interacts with MYO6 using the GH2 domain, ${ }^{13-15}$ which is well conserved between GIPC1 and GIPC3 orthologs (Figure 1d). Taken together, these facts suggest that GIPC3 might directly interact with MYO6 to regulate sensorineural signaling in the cochlea of the inner ear.

It is interesting to ponder what the cargo of the putative GIPC3-MYO6 complex may be. Disorientation of the stereocilia bundle of sensory hair cells in Gipc3 mutant mice ${ }^{11}$ is similar to a 'Frizzled' phenotype in the wing hair of Drosophila, which is caused by mutations of planar cell polarity genes, such as frizzled and vang. ${ }^{2,84-87}$ Xenopus Gipc2 directly interacts with Fzd3 and Fzd7, which are Xenopus homologs of Drosophila Frizzled. ${ }^{16}$ Mouse Gipc1 directly interacts with Vangl2, which is a mouse homolog of Drosophila Vang. ${ }^{53,86,88}$ As the PDZ domain is also well conserved among GIPC family members, Frizzled and Vangl family members might be cargoes of the GIPC3-MYO6 complex. To confirm this, PZD ligands for GIPC3 in sensory hair cells should be elucidated.

Rat Gipc1 directly interacts with dopamine receptors, such as DRD2 and DRD3, ${ }^{40,89}$ and Drosophila Gipc is expressed in dopaminergic neurons. ${ }^{23}$ Germ-line mutations of the human DRD2 gene occur in myoclonus dystonia, ${ }^{90}$ while allelic 
variation of the human DRD3 gene is associated with schizophrenia ${ }^{91}$ and essential tremor. ${ }^{92}$ In addition, as juveniles Gipc3 mutant mice hyper-react to acoustic stimulation by running around in an uncontrolled manner and having seizures, but they become resistant to loud noise at 6 weeks old, owing to the progression of hearing impairment. ${ }^{11}$ Germline mutations of GIPC family genes in neurological diseases, such as myoclonus dystonia, schizophrenia, essential tremor and juvenile epilepsy, might be discovered based on wholegenome or whole-exome sequencing.

GIPC1 upregulation in breast and pancreatic cancers leads to tumor proliferation through IGF1R stabilization and tumor invasion through integrin recycling, whereas GIPC1 downregulation in cervical cancer results in decreased sensitivity to cytostatic signaling through TGF $\beta$ R3 destabilization. CR1023 and its derivatives, which block the interaction between GIPC1 and IGF1R, inhibit proliferation of IGF1R-dependent tumors. However, these GIPC1 inhibitors might promote proliferation of TGF $\beta$-sensitive tumors. Patients should be rigorously selected for clinical application of GIPC1 inhibitors, including CR1023 and its derivatives. Specific inhibitors of GIPC1 targets, such as the small-molecule IGF1R inhibitor and anti-IGF1R human antibody, might be preferable as therapeutic choices for cancer patients.

\section{CONFLICT OF INTEREST}

The author declares no conflict of interest.

\section{ACKNOWLEDGEMENTS}

This work was supported in part by a grant-in-aid for the National Cancer Center Research and Development Fund.

1 De Vries L, Lou X, Zhao G, Zheng B, Farquhar MG. GIPC, a PDZ domain containing protein, interacts specifically with the $C$ terminus of RGS-GAIP. Proc Natl Acad Sci USA 1998; 95: 12340-12345.

2 Kirikoshi $\mathrm{H}$, Katoh M. Molecular cloning and characterization of human GIPC2, a novel gene homologous to human GIPC1 and Xenopus Kermit. Int J Oncol 2002; 20: 571-576.

3 Saitoh T, Mine T, Katoh M. Molecular cloning and characterization of human GIPC3, a novel gene homologous to human GIPC1 and GIPC2. Int $J$ Oncol 2002; 20: 577-582.

4 Katoh M. GIPC gene family. Int J Mol Med 2002; 9: 585-589.

5 Rousset R, Fabre S, Desbois C, Bantignies F, Jalinot P. The C-terminus of the HTLV-1 Tax oncoprotein mediates interaction with the PDZ domain of cellular proteins. Oncogene 1998; 16: 643-654.

6 Cai H, Reed RR. Cloning and characterization of neuropilin-1-interacting protein: a PSD-95/DIg/ZO-1 domain-containing protein that interacts with the cytoplasmic domain of neuropilin-1. J Neurosci 1999; 19: 6519-6527.

7 Bunn R, Jensen M, Reed B. Protein interactions with the glucose transporter binding protein GLUT1CBP that provide a link between GLUT1 and the cytoskeleton. Mol Biol Cell 1999; 10: 819-832.

8 Wang LH, Kalb RG, Strittmatter SM. A PDZ protein regulates the distribution of the transmembrane semaphorin, M-SemF. J Biol Chem 1999; 274: 14137-14146.

9 Gao Y, Li M, Chen W, Simons M. Synectin, syndecan-4 cytoplasmic domain binding PDZ protein, inhibits cell migration. J Cell Physiol 2000; 184: 373-379.

10 Ligensa T, Krauss S, Demuth D, Schumacher R, Camonis J, Jaques G et al. A PDZ domain protein interacts with the $\mathrm{C}$-terminal tail of the insulin-like growth factor-1 receptor but not with the insulin receptor. J Biol Chem 2001; 276: 33419-33427.
11 Charizopoulou N, Lelli A, Schraders M, Ray K, Hildebrand MS, Ramesh A et al. Gipc3 mutations associated with audiogenic seizures and sensorineural hearing loss in mouse and human. Nat Commun 2011; 2: 201.

12 Rehman AU, Gul K, Morell RJ, Lee K, Ahmed ZM, Riazuddin S et al. Mutations of GIPC3 cause nonsyndromic hearing loss DFNB72 but not DFNB81 that also maps to chromosome 19p. Hum Genet 2011; 130: 759-765.

13 Reed BC, Cefalu C, Bellaire BH, Cardelli JA, Louis T, Salamon J et al. GLUT1CBP(TIP2/GIPC1) interactions with GLUT1 and myosin VI: evidence supporting an adapter function for GLUT1CBP. Mol Biol Cell 2005; 16: 4183-4201.

14 Naccache SN, Hasson T, Horowitz A. Binding of internalized receptors to the PDZ domain of GIPC/synectin recruits myosin VI to endocytic vesicles. Proc Natl Acad Sci USA 2006; 103: 12735-12740.

15 Arden SD, Puri C, Au JS, Kendrick-Jones J, Buss F. Myosin VI is required for targeted membrane transport during cytokinesis. Mol Biol Cell 2007; 18: 4750-4761.

16 Tan C, Deardorff MA, Saint-Jeannet JP, Yang J, Arzoumanian A, Klein PS. Kermit, a frizzled interacting protein, regulates frizzled 3 signaling in neural crest development. Development 2001; 128: 3665-3674.

17 Wu J, O'Donnell M, Gitler AD, Klein PS. Kermit 2/XGIPC, an IGF1 receptor interacting protein, is required for IGF signaling in Xenopus eye development. Development 2006; 133: 3651-3660.

18 Vamathevan JJ, Hasan S, Emes RD, Amrine-Madsen H, Rajagopalan D, Topp SD et al. The role of positive selection in determining the molecular cause of species differences in disease. BMC Evol Biol 2008; 8: 273.

19 Spicer E, Suckert C, Al-Attar H, Marsden M. Integrin $\alpha 5 \beta 1$ function is regulated by XGIPC/kermit2 mediated endocytosis during Xenopus laevis gastrulation. PLOS ONE 2010; 5: e10665.

20 Hermans K, Claes F, Vandevelde W, Zheng W, Geudens I, Orsenigo F et al. Role of synectin in lymphatic development in zebrafish and frogs. Blood 2010; 116: 3356-3366.

21 Ren N, Zhu C, Lee H, Adler PN. Gene expression during Drosophila wing morphogenesis and differentiation. Genetics 2005; 171: 625-638.

22 Djiane A, Mlodzik M. The Drosophila GIPC homologue can modulate myosin based processes and planar cell polarity but is not essential for development. PLOS ONE 2010; 5: e11228.

$23 \mathrm{Kim}$ J, Lee S, Ko S, Kim-Ha J. dGIPC is required for the locomotive activity and longevity in Drosophila. Biochem Biophys Res Commun 2010; 402: 565-570.

$24 \mathrm{Mu}$ Y, Huang H, Liu S, Cai P, Gao Y. Molecular characterization and ligand binding specificity of the PDZ domain-containing protein GIPC3 from Schistosoma japonicum. Parasit Vectors 2012; 5: 227.

25 Kirikoshi H. Katoh M. Expression of human GIPC1 in normal tissues, cancer cell lines, and primary tumors. Int J Mol Med 2002; 9: 509-513.

26 Heinzelmann-Schwarz VA, Gardiner-Garden M, Henshall SM, Scurry J, Scolyer RA, Davies MJ et al. Overexpression of the cell adhesion molecules DDR1, Claudin 3, and Ep-CAM in metaplastic ovarian epithelium and ovarian cancer. Clin Cancer Res 2004; 10: 4427-4436.

27 Muders MH, Dutta SK, Wang L, Lau JS, Bhattacharya R, Smyrk TC et al. Expression and regulatory role of GAIP-interacting protein GIPC in pancreatic adenocarcinoma. Cancer Res 2006; 66: 10264-10268.

28 Yavelsky V, Rohkin S, Shaco-Levy R, Tzikinovsky A, Amir T, Kohn $\mathrm{H}$ et al. Native human autoantibodies targeting GIPC1 identify differential expression in malignant tumors of the breast and ovary. BMC Cancer 2008; 8: 247

29 Rudchenko S, Scanlan M, Kalantarov G, Yavelsky V, Levy C, Estabrook A et al. A human monoclonal autoantibody to breast cancer identifies the PDZ domain containing protein GIPC1 as a novel breast cancer-associated antigen. BMC Cancer 2008; 8: 248.

30 Kuang SQ, Tong WG, Yang H, Lin W, Lee MK, Fang ZH et al. Genome-wide identification of aberrantly methylated promoter associated $\mathrm{CpG}$ islands in acute lymphocytic leukemia. Leukemia 2008; 22: 1529-1538.

31 Muders MH, Vohra PK, Dutta SK, Wang E, Ikeda Y, Wang L et al. Targeting GIPC/synectin in pancreatic cancer inhibits tumor growth. Clin Cancer Res 2009; 15: 4095-4103.

32 Choi JS, Paek AR, Kim SY, You HJ. GIPC mediates the generation of reactive oxygen species and the regulation of cancer cell proliferation by insulin-like growth factor-1/IGF-1R signaling. Cancer Lett 2010; 294: 254-263.

33 Chittenden TW, Pak J, Rubio R, Cheng $\mathrm{H}$, Holton K, Prendergast $\mathrm{N}$ et al. Therapeutic implications of GIPC1 silencing in cancer. PLOS ONE 2010; 5: e15581. 
34 Fejzo MS, Ginther C, Dering J, Anderson L, Venkatesan N, Konecny G et al. Knockdown of ovarian cancer amplification target ADRM1 leads to downregulation of GIPC1 and upregulation of RECK. Genes Chromosomes Cancer 2011; 50: 434-441.

$35 \mathrm{Hu}$ LA, Chen W, Martin NP, Whalen EJ, Premont RT, Lefkowitz RJ. GIPC interacts with the $\beta 1$-adrenergic receptor and regulates $\beta 1$-adrenergic receptor-mediated ERK activation. J Biol Chem 2003; 278: 26295-26301.

36 Lin DC, Quevedo C, Brewer NE, Bell A, Testa JR, Grimes ML et al. APPL1 associates with TrkA and GIPC1 and is required for nerve growth factor-mediated signal transduction. Mol Cell Biol 2006; 26: 8928-8941.

37 Varsano T, Dong MQ, Niesman I, Gacula H, Lou X, Ma T et al. GIPC is recruited by APPL to peripheral TrkA endosomes and regulates TrkA trafficking and signaling. Mol Cell Biol 2006; 26: 8942-8952.

38 Schenck A, Goto-Silva L, Collinet C, Rhinn M, Giner A, Habermann B et al. The endosomal protein Appl1 mediates Akt substrate specificity and cell survival in vertebrate development. Cell 2008; 133: 486-497.

39 Bohlson SS, Zhang M, Ortiz CE, Tenner AJ. CD93 interacts with the PDZ domain-containing adaptor protein GIPC: implications in the modulation of phagocytosis. J Leukoc Biol 2005; 77: 80-89.

40 Jeanneteau F, Guillin O, Diaz J, Griffon N, Sokoloff P. GIPC recruits GAIP (RGS19) to attenuate dopamine D2 receptor signaling. Mol Biol Cell 2004; 15: 4926-4937.

41 Lee NY, Ray B, How T, Blobe GC. Endoglin promotes transforming growth factor $\beta$-mediated Smad 1/5/8 signaling and inhibits endothelial cell migration through its association with GIPC. J Biol Chem 2008; 283: 32527-32533.

42 Tani TT, Mercurio AM. PDZ interaction sites in integrin $\alpha$ subunits: TIP-2/ GIPC binds to a type I recognition sequence in $\alpha 6 \mathrm{~A} / \alpha 5$ and a novel sequence in a6B. J Biol Chem 2001; 276: 36535-36542.

43 Hirakawa T, Galet C, Kishi M, Ascoli M. GIPC binds to the human lutropin receptor (hLHR) through an unusual PDZ domain binding motif, and it regulates the sorting of the internalized human choriogonadotropin and the density of cell surface hLHR. J Biol Chem 2003; 278 : 49348-49357.

44 Gotthardt G, Trommsdorff M, Nevitt MF, Shelton J, Richardson JA, Stockinger $W$ et al. Interactions of the low density lipoprotein receptor gene family with cytosolic adaptor and scaffold proteins suggest diverse biological functions in cellular communication and signal transduction. J Biol Chem 2000; 275: 25616-25624.

45 Pellet-Many C, Frankel P, Jia H, Zachary I. Neuropilins: structure, function and role in disease. Biochem J 2008; 411: 211-226.

46 Prud'homme GJ, Glinka Y. Neuropilins are multifunctional coreceptors involved in tumor initiation, growth, metastasis and immunity. Oncotarget 2012; 3: 921-939.

47 Lou X, Yano H, Lee F, Chao MV, Farquhar MG. GIPC and GAIP form a complex with TrkA: a putative link between $G$ protein and receptor tyrosine kinase pathways. Mol Biol Cell 2001; 12: 615-627.

48 Blobe GC, Liu X, Fang SJ, How T, Lodish HF. A novel mechanism for regulating transforming growth factor $\beta$ (TGF- $\beta$ ) signaling: functional modulation of type III TGF- $\beta$ receptor expression through interaction with the PDZ domain protein, GIPC. J Biol Chem 2001; 276: 39608-39617.

49 Finger EC, Turley RS, Dong M, How T, Fields TA, Blobe GC. T RRIII suppresses non-small cell lung cancer invasiveness and tumorigenicity. Carcinogenesis 2008; 29: 528-535.

50 Townsend TA, Robinson JY, How T, DeLaughter DM, Blobe GC, Barnett JV. Endocardial cell epithelial-mesenchymal transformation requires Type III TGF $\beta$ receptor interaction with GIPC. Cell Signal 2012; 24: 247-256.

51 Awan A, Lucic MR, Shaw DM, Sheppard F, Westwater C, Lyons SA et al. 5T4 interacts with TIP-2/GIPC, a PDZ protein, with implications for metastasis. Biochem Biophys Res Commun 2002; 290: 1030-1036.

52 Liu TF, Kandala G, Setaluri V. PDZ domain protein GIPC interacts with the cytoplasmic tail of melanosomal membrane protein gp75 (tyrosinaserelated protein-1). J Biol Chem 2001; 276: 35768-35777.

53 Giese AP, Ezan J, Wang L, Lasvaux L, Lembo F, Mazzocco C et al. Gipc1 has a dual role in Vangl2 trafficking and hair bundle integrity in the inner ear. Development 2012; 139: 3775-3785.

54 Razanskas R, Sasnauskas K. Interaction of hepatitis B virus core protein with human GIPC1. Arch Virol 2010; 155: 247-250.

55 Favre-Bonvin A, Reynaud C, Kretz-Remy C, Jalinot P. Human papillomavirus type 18 E6 protein binds the cellular PDZ protein TIP-2/GIPC, which is involved in transforming growth factor beta signaling and triggers its degradation by the proteasome. J Virol 2005; 79: 4229-4237.

56 Buss F, Kendrick-Jones J. How are the cellular functions of myosin V regulated within the cell? Biochem Biophys Res Commun 2008; 369: 165-175.

57 McMahon HT, Boucrot E. Molecular mechanism and physiological functions of clathrin-mediated endocytosis. Nat Rev Mol Cell Biol 2011; 12: 517-533.

58 Huotari J, Helenius A. Endosome maturation. EMBO J 2011; 30: 3481-3500.

59 Caswell PT, Vadrevu S, Norman JC. Integrins: masters and slaves of endocytic transport. Nat Rev Mol Cell Biol 2009; 10: 843-853.

60 Torres VA, Stupack DG. Rab5 in the regulation of cell motility and invasion. Curr Protein Pept Sci 2011; 12: 43-51.

61 Valdembri D, Caswell PT, Anderson KI, Schwarz JP, König I, Astanina E et al. Neuropilin-1/GIPC1 signaling regulates $\alpha 5 \beta 1$ integrin traffic and function in endothelial cells. PLoS Biol 2009; 7: e25.

62 Avraham R, Yarden Y. Feedback regulation of EGFR signalling: decision making by early and delayed loops. Nat Rev Mol Cell Biol 2011; 12 104-117.

63 Wiley HS, Burke PM. Regulation of receptor tyrosine kinase signaling by endocytic trafficking. Traffic 2001; 2: 12-18.

64 Katoh M. FGFR2 abnormalities underlie a spectrum of bone, skin, and cancer pathologies. J Invest Dermatol 2009; 129: 1861-1867.

65 Lagerström MC, Schiöth HB. Structural diversity of G protein-coupled receptors and significance for drug discovery. Nat Rev Drug Discov 2008; 7: 339-357.

66 Katoh M, Katoh M. WNT signaling pathway and stem cell signaling network. Clin Cancer Res 2007; 13: 4042-4045.

67 Lappano R, Maggiolini M. G protein-coupled receptors: novel targets for drug discovery in cancer. Nat Rev Drug Discov 2011; 10: 47-60.

68 Irannejad R, Tomshine JC, Tomshine JR, Chevalier M, Mahoney JP, Steyaert $\mathrm{J}$ et al. Conformational biosensors reveal GPCR signalling from endosomes. Nature 2013; 495: 534-538.

69 Sirmaci A, Edwards YJ, Akay H, Tekin M. Challenges in whole exome sequencing: an example from hereditary deafness. PLOS ONE 2012; 7: e32000.

70 Saitoh T, Mine T, Katoh M. Molecular cloning and characterization of mouse Gipc3. Int J Mol Med 2002; 9: 251-256.

71 Patra CR, Rupasinghe CN, Dutta SK, Bhattacharya S, Wang E, Spaller MR et al. Chemically modified peptides targeting the PDZ domain of GIPC as a therapeutic approach for cancer. ACS Chem Biol 2012; 7: 770-779.

72 Kirikoshi H, Katoh M. Up-regulation of GIPC2 in human gastric cancer Int J Oncol 2002; 20: 1183-1187.

73 Fernandez-Ranvier GG, Weng J, Yeh R, Khanafshar E, Suh I, Barker C et al. Identification of biomarkers of adrenocortical carcinoma using genomewide gene expression profiling. Arch Surg 2008; 143: 841-846.

74 Mercier I, Casimiro MC, Zhou J, Wang C, Plymire C, Bryant KG et al. Genetic ablation of caveolin-1 drives estrogen-hypersensitivity and the development of DCIS-like mammary lesions. Am J Pathol 2009; 174: 1172-1190.

75 Kendrick H, Regan JL, Magnay FA, Grigoriadis A, Mitsopoulos C, Zvelebil $\mathrm{M}$ et al. Transcriptome analysis of mammary epithelial subpopulations identifies novel determinants of lineage commitment and cell fate. BMC Genomics 2008; 9: 591.

76 Stransky N, Egloff AM, Tward AD, Kostic AD, Cibulskis K, Sivachenko A et al. The mutational landscape of head and neck squamous cell carcinoma. Science 2011; 333: 1157-1160.

77 Muzny DM, Bainbridge MN, Chang K, Dinh HH, Drummond JA, Fowler G et al. Comprehensive molecular characterization of human colon and rectal cancer. Nature 2012; 487: 330-337.

78 Berger MF, Hodis E, Heffernan TP, Deribe YL, Lawrence MS, Protopopov A et al. Melanoma genome sequencing reveals frequent PREX2 mutations. Nature 2012; 485: 502-506.

79 Bell D, Berchuck A, Birrer M, Chien J, Cramer D, Dao F et al. Integrated genomic analyses of ovarian carcinoma. Nature 2011; 474: 609-615.

80 Wood LD, Parsons DW, Jones S, Lin J, Sjöblom T, Leary RJ et al. The genomic landscapes of human breast and colorectal cancers. Science 2007; 318: 1108-1113.

81 Melchionda S, Ahituv N, Bisceglia L, Sobe T, Glaser F, Rabionet R et al. MYO6, the human homologue of the gene responsible for deafness in Snell's waltzer mice, is mutated in autosomal dominant nonsyndromic hearing loss. Am J Hum Genet 2001; 69: 635-640. 
82 Ahmed ZM, Morell RJ, Riazuddin S, Gropman A, Shaukat S, Ahmad MM et al. Mutations of MYO6 are associated with recessive deafness, DFNB37. Am J Hum Genet 2003; 72: 1315-1322.

83 Avraham KB, Hasson T, Steel KP, Kingsley DM, Russell LB, Mooseker MS et al. The mouse Snell's waltzer deafness gene encodes an unconventional myosin required for structural integrity of inner ear hair cells. Nat Genet 1995; 11: 369-375.

84 Strutt H, Strutt D. Nonautonomous planar polarity patterning in Drosophila: dishevelled-independent functions of frizzled. Dev Cell 2002; 3: 851-863.

85 Mlodzik M. Planar cell polarization: do the same mechanisms regulate Drosophila tissue polarity and vertebrate gastrulation? Trends Genet 2002; 18: 564-571.

86 Katoh M. WNT/PCP signaling pathway and human cancer. Oncol Rep 2005; 14: 1583-1588.

87 Axelrod JD. Progress and challenges in understanding planar cell polarity signaling. Semin Cell Dev Biol 2009; 20: 964-971.

88 Katoh M. Strabismus (STB)/Vang-like (VANGL) gene family. Int J Mol Med 2002; 10: 11-15.
89 Jeanneteau F, Diaz J, Sokoloff P, Griffon N. Interactions of GIPC with dopamine D2, D3 but not D4 receptors define a novel mode of regulation of G protein-coupled receptors. Mol Biol Cell 2004; 15: 696-705.

90 Klein C, Gurvich N, Sena-Esteves M, Bressman S, Brin MF, Ebersole BJ et al. Evaluation of the role of the D2 dopamine receptor in myoclonus dystonia. Ann Neurol 2000; 47: 369-373.

91 Crocq MA, Mant R, Asherson P, Williams J, Hode Y, Mayerova A et al. Association between schizophrenia and homozygosity at the dopamine D3 receptor gene. J Med Genet 1992; 29: 858-860.

92 Lucotte G, Lagarde JP, Funalot B, Sokoloff P. Linkage with the Ser9Gly DRD3 polymorphism in essential tremor families. Clin Genet 2006; 69: 437-440.

(c) (i) (2) $\odot$ This work is licensed under a Creative Commons Attribution-NonCommercial-NoDerivs 3.0 Unported License. To view a copy of this license, visit http:// creativecommons.org/licenses/by-nc-nd/3.0/ 